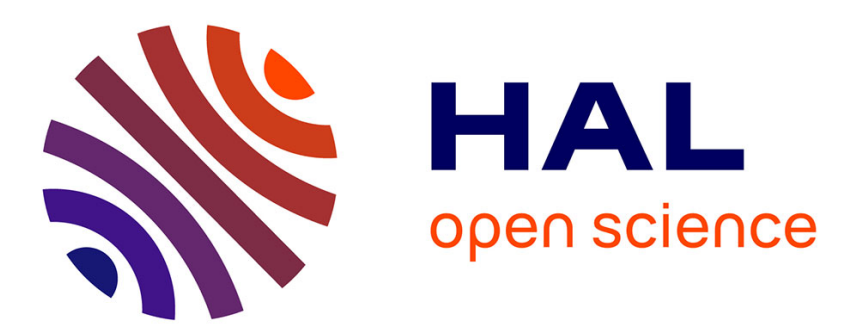

\title{
Status of HIGISOL a new version equipped with SPIG and electric field guidance
}

R. Béraud, G. Canchel, A. Emsallem, P. Dendooven, J. Huikari, W. Huang, Y. Wang, K. Peraejaervi, S. Rinta-Antila, A. Jokinen, et al.

\section{- To cite this version:}

R. Béraud, G. Canchel, A. Emsallem, P. Dendooven, J. Huikari, et al.. Status of HIGISOL a new version equipped with SPIG and electric field guidance. Hyperfine Interactions, 2001, 132, pp.485-490. in2p3-00009790

\author{
HAL Id: in2p3-00009790 \\ https://hal.in2p3.fr/in2p3-00009790
}

Submitted on 19 Nov 2001

HAL is a multi-disciplinary open access archive for the deposit and dissemination of scientific research documents, whether they are published or not. The documents may come from teaching and research institutions in France or abroad, or from public or private research centers.
L'archive ouverte pluridisciplinaire HAL, est destinée au dépôt et à la diffusion de documents scientifiques de niveau recherche, publiés ou non, émanant des établissements d'enseignement et de recherche français ou étrangers, des laboratoires publics ou privés. 


\title{
Article
}

\section{Status of HIGISOL, a new version equipped with SPIG and electric field guidance*}

\author{
R. Béraud ${ }^{\text {a }}$, G. Canchel $^{\text {a }}$, A. Emsallem ${ }^{\text {a }}$, P. Dendooven ${ }^{\text {b }}$, J. Huikari ${ }^{\text {b }}$, \\ W. Huang ${ }^{b}$, Y. Wang ${ }^{\text {b }}$, K. Peräjärvi ${ }^{b}$, S. Rinta-Antila ${ }^{b}$, A. Jokinen ${ }^{b}$, \\ V.S. Kolhinen ${ }^{\mathrm{b}}$, A. Nieminen ${ }^{\mathrm{b}}$, H. Penttilä ${ }^{\mathrm{b}}$, J. Szerypo ${ }^{\mathrm{b}}$, J. Äystö ${ }^{\mathrm{b}}$, \\ B. Bruyneel ${ }^{\mathrm{c}}$ and A. Popov ${ }^{\mathrm{d}}$ \\ ${ }^{a}$ Institut de Physique Nucléaire de Lyon, IN2P3-CNRS et Université Claude Bernard Lyon 1, \\ 43, Bd du 11 Novembre 1918, F-69622 Villeurbanne Cedex \\ ${ }^{b}$ Department of Physics, University of Jyväskylä, \\ P.O. Box 35, 40351 Jyväskylä, Finland \\ ${ }^{c}$ Instituut voor Kern-en Stralingsfysica, K.U. Leuven, \\ Celestijnenlaan 200D, B-3001 Leuven, Belgium \\ ${ }^{d}$ St Petersburg Nuclear Physics Institute, Gatchina \\ 188350 St Petersburg, Russia
}

A new HIGISOL chamber devoted to the study of short-lived products from heavy-ion-induced fusion-evaporation reactions is proposed. It enables, via the extraction of ions by means of a SPIG (SextuPole rf Ion Guide), to improve the Mass Resolving Power by a factor 2.5 compared to the previous system using a skimmer-ring assembly. The gas cell was also equipped with an electric field for faster transportation of recoiling ions to the nozzle where they are ejected with the gas jet. The first results obtained both with a radioactive $\alpha$-source and cyclotron beam will be reported.

\section{Introduction}

The HIGISOL system implemented at the $\mathrm{K}=130$ cyclotron in Jyväskylä since 1996 gives readily, for short-lived products of H.I. induced fusionevaporation reactions, a yield of $\sim 100$ ions/(s.mbarn. $\left.\mu \mathrm{A}_{\text {part }}\right)[1]$. The technique is fast (ms range), applicable to all elements, but, as the overall efficiency

* This work has been supported by the Human Potential Programme and Access to Research Infrastructures of the European Union 
is rather low $(\sim 1 \%)$, its use is presently restricted to very refractory elements where no ISOL techniques can compete. The survival time of singly-charged ions is reduced to a few $\mathrm{ms}$ in high pressure He buffer gas needed to stop high energy recoils. Therefore, it is of utmost importance to diminish the mean evacuation time of reaction products and for this purpose, the addition of an electric field guidance has proven to be an appropriate solution[2].

\section{Experimental results}

\subsection{Description of the new chamber}

Figure 1 shows the new target- and recoil chamber assembly installed online at the Jyväskylä cyclotron. The main differences, regarding our previous set-up described in[1] are both a larger He pressurized recoil chamber with its axis parallel to the He flow and a primary beam stopper outside (replacing the channel). According to the He flow simulations using the techniques described

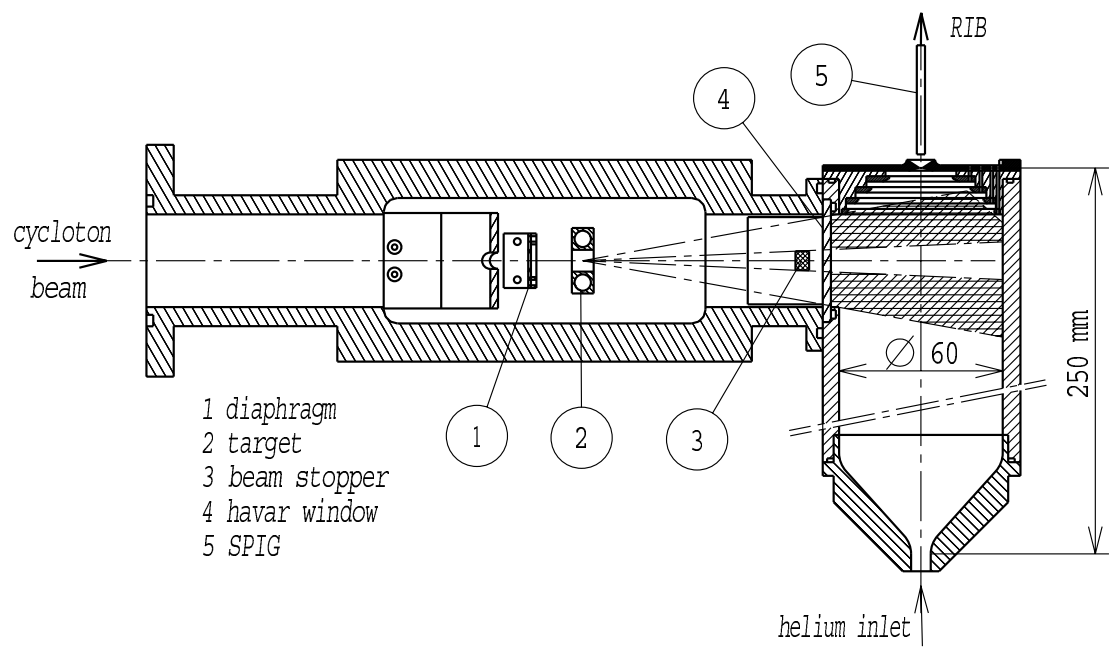

Figure 1. Schematic drawing of the new HIGISEL chamber.

in[3], this long chamber should provide much more homogeneous He evacuation than our previous one[4]. In counterpart, the effective stopping volume is reduced from $\sim 100 \mathrm{~cm}^{3}$ to $\sim 60 \mathrm{~cm}^{3}$. In order to prevent the cyclotron H.I. beam from interacting with buffer gas, we have installed a cylindrical beam stopper $\left(\phi_{e}=7\right.$ 
$\mathrm{mm}$ ) placed at a $5 \mathrm{~mm}$ distance from the havar entrance window (thickness $=2$ $\mathrm{mg} / \mathrm{cm}^{2}$ ). In figure 2 , it is shown that the efficiency remains constant within a large range of ${ }^{36} \mathrm{Ar}$ beam intensity (0.8 to $\left.4.010^{12} \mathrm{pps}\right)$. This clearly demonstrates that the "plasma effect" (if any !) is now kept independent of the primary beam intensity. Moreover, this intensity is no longer limited by the exit window survival as it was in our previous chamber with the channel.

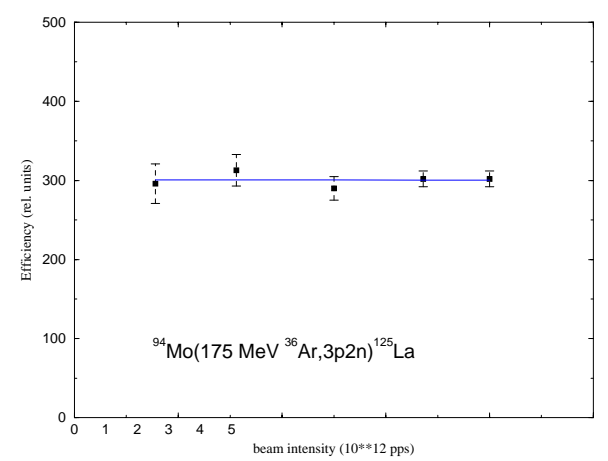

Figure 2. Relative efficiency of HIGISOL as a function of ${ }^{36}$ Ar primary beam intensity.

\section{2. $R F$ sextupole instead of skimmer}

The transportation of ions from the pressurized chamber to the high vacuum region using a radiofrequency sextupole was proposed in ref[5] and also in ref[6] at Jyväskylä. Such a device has been successfully installed at Leuven[7]. The SPIG (SextuPole Ion Guide) allows a much larger pumping speed of buffer gas in the extraction region providing lower density and therefore less collisions between gas atoms and ions to be guided towards the acceleration stage. Consequently, this results in two advantages : -i) a much smaller energy spread $(\sim 1 \mathrm{eV})$ compared to the skimmer system $(\sim 100 \mathrm{eV})$ and-ii) the possibility to use higher buffer gas pressure, increasing thus the stopping efficiency of the cell. In case of $500 \mathrm{hPa} \mathrm{He}$ pressure, the Mass Resolving Power (MRP) obtained with the SPIG is about 1100 whereras it was only $~ 400$ using the skimmer. Moreover, the MRP is independent of He pressure. It is the result of a soft collisions regime in the extraction-SPIG region and this could also explain the large amount of molecular ions, formed in the recoil chamber, which can fly through the $\mathrm{RF}$ sextupole without dissociation. Adding a DC voltage (up to $225 \mathrm{~V})$ to the $\mathrm{RF}$ one $\left(U_{R F}=600 \mathrm{~V}, \nu_{R F}=2.2\right.$ 
$\mathrm{MHz}$ ) didn't help to dissoiate them. For Ce and La elements the amount of $\mathrm{CeO}^{+}$and $\mathrm{LaO}^{+}$ions eompared to $\mathrm{Ce}^{+}$and $\mathrm{La}^{+}$ones was strongly dependent on the grade of the gas used. The ratio $\mathrm{M}^{+} /\left(\mathrm{M}^{+}+\mathrm{MO}^{+}\right)$eould vary in a very broad range $(95 \%-5 \%)$.

\subsection{Electric field guidance}

Figure 3 shows a detailed drawing of the ensemble of eleetrodes designed to get a foeusing field towards the exit hole. A simulation of the equipotential surfaees has been obtained using the SIMION (vers. 6.0) eode ineluding a viseuous foree. The eleetrodes are made of stainless steel whereas the insulator is standard araldite glue.

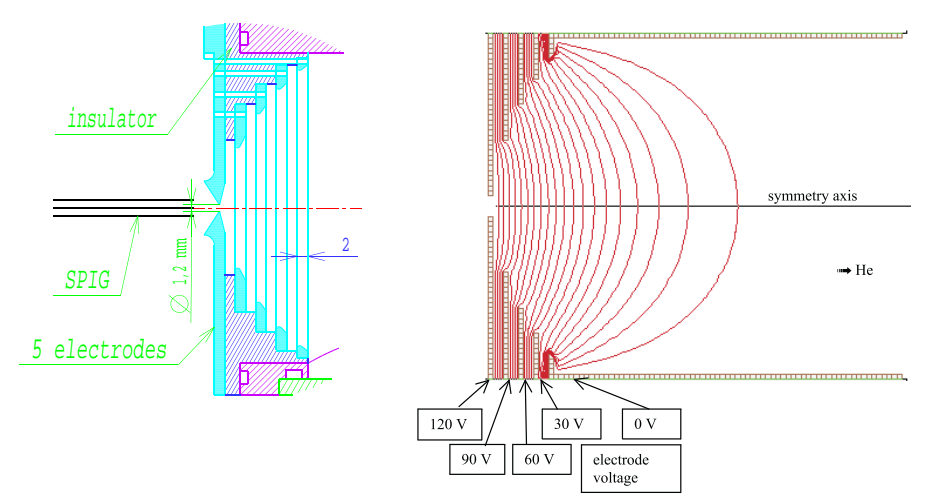

Figure 3. Drawing of the electrodes system and mapping of equipotential curves.

\subsubsection{Off-line tests}

A ${ }^{223} \operatorname{Ra}\left(T_{1 / 2}=11.43 \mathrm{~d}\right) \alpha$-souree is placed at the tip of a needle movable along the symmetry axis of the ehamber. This allows absolute effieieney measurement as a funetion of the extraetion hole-souree distanee. Figure 4 shows the ability of the eleetrie field to extraet, with eonstant effieieney, mass-separated ions $\left({ }^{219} \mathrm{Rn}\right)$ whieh are thermalized far away from the exit hole (up to $\left.4 \mathrm{em}\right)$. However the drop of effieieney at short distanee (eompared to the "no field" ease) should be avoided providing a more foeusing field very elose to the nozzle. 


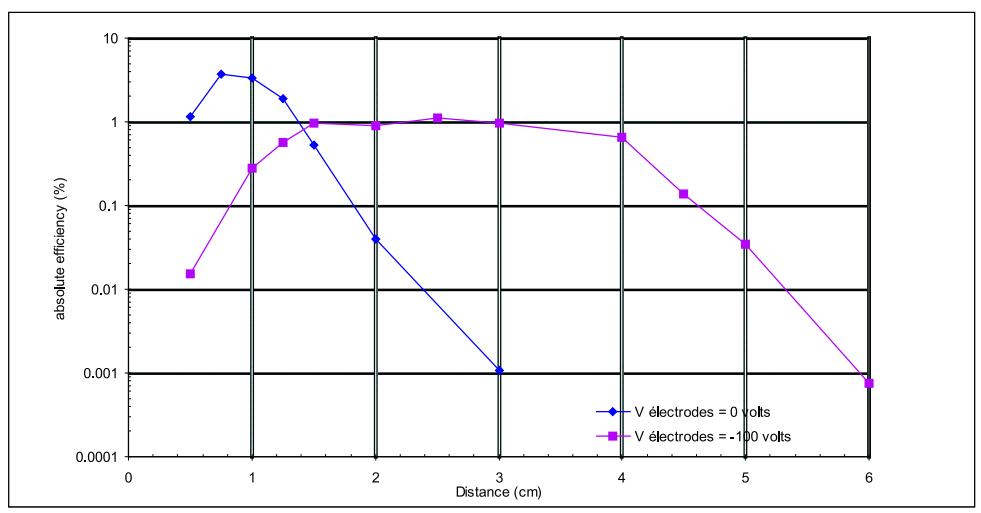

Figure 4. Absolute efficiency for ${ }^{219}$ Rn recoils as a function of exit hole-source distance.

\subsubsection{On-line tests}

The efficiency for recoils from the ${ }^{223} \mathrm{Ra}$ source has been measured as a function of field strength. In presence of the cyclotron beam, we note a decrease of the yield when the voltage is increasing whatever the recoils are. In figure 5 is presented the number of $\alpha$ counts as a function of the electric field value. It is worth noting that the distance source-exit hole is large enough so that the transit time of ions ( $\geq 50 \mathrm{~ms}$ without field) is much longer than the survival time $(2-3 \mathrm{~ms})$. The "no beam" curve in figure 5 shows that with $\mathrm{V}=0$, the ions are not extracted. A special point to be emphazised is that with the beam, an appreciable amount of activity is extracted. The ${ }^{219} \mathrm{Rn}$ ions are re-ionised by the plasma produced via the reaction products when stopping in He. In this case the mechanism is much similar as for a classical plasma source. The number of

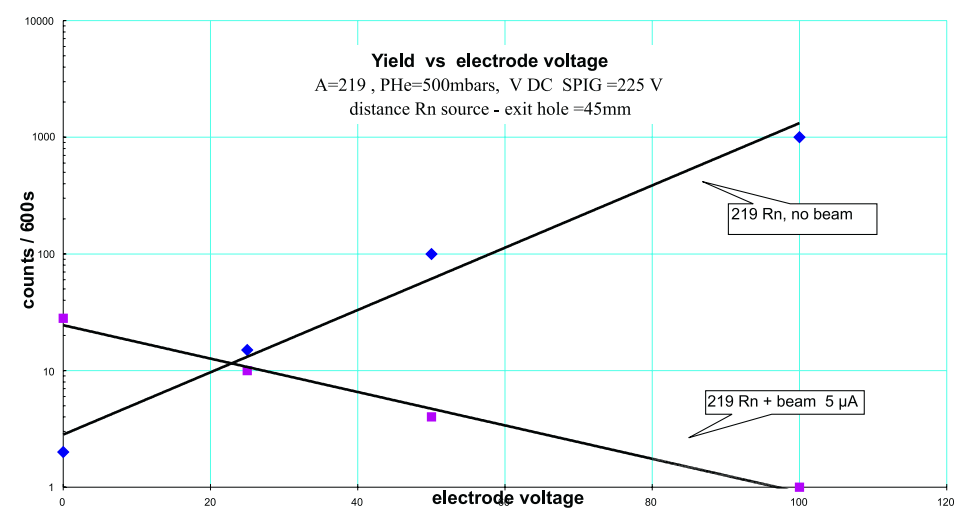

Figure 5. Relative efficiency as a function of electric field strength. 
ions delivered by the source being constant, this is an experimental evidence of the occurrence of reionization processes via collisions with recoiling nuclei and secondary particles produced by the H.I. beam. This effect has been previously mentioned in our original work about HIGISOL[8].

\section{Conclusion}

In this work we have shown the advantages of the RF sextupole extraction system which provides much better MRP and that the stopper enables the use of very intense H.I. beams. The electric field allows to collect ions in a much larger volume, a revised version of our electrodes system (under construction) should avoid losses at short distance and therefore improve efficiency in the near future. In presence of beam, the situation is much more complex due to field perturbations induced very likely by the secondary particles, non-suppressed beam and subsequent ionisation of the buffer gas.

\section{References}

[1] P. Dendooven, R. Béraud, E. Chabanat, A. Emsallem, A. Honkanen, M. Huhta, A. Jokinen, G. Lhersonneau, M. Oinonen, H. Penttilä, K. Peräjärvi, J.C. Wan_, J. Äystö, Nucl. Instr. \& Meth. Phys. Res., A408 (1998) 530.

[2] H. Backe, K. Eberhardt, R. Feldmann, M. Hies, H. Kunz, W. Lauth, R. Martin, H. Schöpe, P. Schwamb, M. Sewtz, P. Thörle, N. Trautmann, S. Zauner, Nucl. Instr. \& Meth. Phys. Res., B126 (1997) 406.

[3] K. Peräjärvi, P. Dendooven, J. Huikari, A. Jokinen, V.S. Kolhinen, A. Nieminen, J. Äystö, Nucl. Instr. \& Meth. Phys. Res., A449 (2000) 427.

[4] R. Béraud, R. Bouvier, G. Canchel, E. Chabanat and A. Emsallem, IPN Lyon 98-99, Report - LYCEN 2000-49, p.52.

[5] H.J. Xu, M. Wada, J. Tanaka, H. Kawakami, I. Katayama and S. Ohtani, Nucl. Instr. \& Meth. Phys. Res., A333 (1993) 274.

[6] A. Lindell and K. Morita, Report 2.16, JYFL, Annual report 1993, p.52.

[7] P. Van den Ber_h, S. Franchoo, J. Gentens, M. Huyse, Yu. A. Kudryavtsev, A. Piechaczek, R. Raabe, I. Reusen, P. Van Duppen, L. Vermeeren, A. Wöhr Nucl. Instr. \& Meth. Phys. Res., B126 (1997) 194.

[8] R. Béraud, A. Emsallem, A. Astier, R. Bouvier, R. Duffait, Y. Le Coz, S. Morier, A. Wojtasiewicz, Yu A. Lazarev, I.V. Shirokovsky, I.N. Izosimov, D. Barnéoud, J. Genevey, A. Gizon, R. Gu_lielmini, G. Mar_otton, J.L. Vieux-Rochaz, Nucl. Instr. \& Meth. Phys. Res., A346 (1994) 196. 